\title{
The impact of hearing loss on the quality of life of elderly adults
}

\author{
This article was published in the following Dove Press journal: \\ Clinical Interventions in Aging \\ 14 June 2012 \\ Number of times this article has been viewed
}

\section{Andrea Ciorba \\ Chiara Bianchini \\ Stefano Pelucchi \\ Antonio Pastore}

ENT and Audiology Department, University Hospital of Ferrara, Ferrara, Italy
Correspondence: Andrea Ciorba ENT and Audiology Department, University Hospital of Ferrara,

C.so Giovecca 203, 44 I00 Ferrara, Italy

Tel +390532 237447

Email andrea.ciorba@unife.it
Abstract: Hearing loss is the most common sensory deficit in the elderly, and it is becoming a severe social and health problem. Especially in the elderly, hearing loss can impair the exchange of information, thus significantly impacting everyday life, causing loneliness, isolation, dependence, and frustration, as well as communication disorders. Due to the aging of the population in the developed world, presbycusis is a growing problem that has been reported to reduce quality of life (QoL). Progression of presbycusis cannot be remediated; therefore, optimal management of this condition not only requires early recognition and rehabilitation, but it also should include an evaluation of QoL status and its assessment.

Keywords: hearing loss, presbycusis, quality of life, elderly

\section{Introduction}

The term "presbycusis" refers to hearing loss that is associated with the cochlear degenerative process of aging. By definition, presbycusis is bilateral, symmetrical, and slowly progressive..$^{1-3}$

Hearing loss is a common problem associated with senescence, and it is likely to become more of an issue with changing population demographics in the developed world. The impact of hearing loss may be profound, with consequences for the social, functional, and psychological well-being of the person.

On one side, our lack of understanding of this disease process and our inability to remediate its progression are important parts of the problem. At present, clinicians can only use family history, the history of onset and progression, and the results of audiometric testing to determine the degree of impairment, to estimate the potential for future hearing loss, and to make recommendations for amplification with hearing aids.

On the other side, optimal management of this condition also should include an evaluation of quality of life (QoL) status and its assessment. This is due to the fact that several studies have already demonstrated that presbycusis may have a negative effect on QoL and psychological well-being - social isolation, depression, anxiety, and even cognitive decline have been reported in affected persons. ${ }^{1-3}$

Despite efforts to understand the disease processes, at present, clinicians are still unable to remediate its progression.

\section{Epidemiology and risk factors of presbycusis: a challenging problem}

Presbycusis is the most common cause of adult hearing deficiency; it is considered the most prevalent sensory impairment in the elderly, affecting individuals aged 75 years 
and older. As our society matures, there are more people living into their $60 \mathrm{~s}, 70 \mathrm{~s}, 80 \mathrm{~s}$, and beyond, due to factors such as improved nutrition and health care. It has been reported that, in the United States, presbycusis affects $40 \%$ of the population older than 75 years of age, and, in our aging society, it is becoming more prevalent. ${ }^{1-5}$ The 1995 UK national study of hearing disorders found that $20 \%$ of adults had some degree of hearing impairment (audiometric threshold greater than $25 \mathrm{~dB}$ ) in the better hearing ear; $75 \%$ of those are over 60 years of age. ${ }^{1-5}$ Recent estimations suggest that the number of senior citizens in the US with significant hearing loss could increase to $35-40$ million by the year $2030 .^{1-5}$

Aging is defined as the biological process of growing old, and intrinsic and extrinsic factors, as well as their interactions, influence the degree and rate at which our hearing ages. Thus, the occurrence of presbycusis is thought to be determined predominantly by genetic factors; however, it also can be influenced by environmental factors, such as noise, ototoxic drugs, alcohol, and diabetes. ${ }^{4-7}$

\section{Methods}

We performed a PubMed database systematic review for peerreviewed articles published between January 2000 and December 2011, matching the terms "hearing loss," "presbycusis," "cochlea," "quality of life," and "elderly." The search retrieved about 50 articles, which we proceeded to investigate.

\section{Quality of life and presbycusis: hearing loss is also a social loss}

Understanding the impact of hearing loss on quality of life is of great importance, as difficulties with communication affect interactions with other people. This is an important aspect of everyday life, which can be seriously impaired in individuals with hearing loss, leading to a perceived reduction of QoL. ${ }^{8,9}$

The term "QoL" is used to evaluate the general well-being of individuals. Considerable agreement exists regarding the idea that the evaluation of QoL is multidimensional: physical well-being, material well-being, social well-being, and emotional well-being. ${ }^{8}$ It has now been reported by several authors that hearing loss is an increasingly important public health problem that has been linked to reduced QoL, as it can impair the exchange of information, significantly impacting daily life, especially for elderly people. Reported effects of presbycusis on QoL are:

- emotional reactions, such as loneliness, isolation, dependence, frustration, depression, anxiety, anger, embarrassment, frustration, and guilt
- behavioral reactions, such as bluffing, withdrawing, blaming, and demanding

- cognitive reactions, such as confusion, difficulty focusing, distracting thoughts, decreased self-esteem, and communication disorders. , $^{8}$

\section{Instruments to evaluate the impact of hearing loss on QoL}

Assessment of QoL deterioration due to hearing loss can be achieved through several instruments, as reported in different studies in the literature. ${ }^{8,9}$ These can be divided into hearing-related QoL instruments (Table 1) and generic QoL instruments.

An example of a hearing-related instrument that incorporates a question specifically designed to assess QoL is the Hearing Handicap Inventory for the Elderly (HHIE). ${ }^{10}$ This is a self-assessment tool designed to measure the effects of hearing impairment on the emotional and social adjustment of elderly people. This inventory is comprised of two subscales: a 13-item subscale that explores the emotional consequences of hearing impairment, and a 12-item subscale that describes both social and situational effects. The HHIE has been judged a reliable and valid tool, as well as an easyto-use questionnaire. ${ }^{8,9}$

The Hearing Handicap Inventory for Adults (HHIA) ${ }^{11}$ is a 25-item survey derived from the original HHIE by Weinstein et al. ${ }^{10}$ It also is composed of a 13-item emotional subscale and a 12 -item socio-situational subscale. ${ }^{11}$

The International Outcomes Inventory - Hearing Aids (IOI-HA) by Cox et al ${ }^{12}$ explores the perceived usefulness of hearing aids. ${ }^{12}$ The IOI-HA is a relatively short test that is easy to administer. Each of its seven questions is designed to target a different outcome domain, which include: usage of hearing aid (number of hours per day of hearing aid use); benefit in terms of improvement in hearing-related activities;

Table I Main specific instruments to evaluate the impact of hearing loss on QoL

\begin{tabular}{llll}
\hline Instrument & Goal & Items & Reference \\
\hline HHIE $^{10}$ & $\begin{array}{l}\text { Measures the effects of hearing } \\
\text { impairment on the emotional and } \\
\text { social adjustment of elderly people }\end{array}$ & 25 & $8-10$ \\
HHIA $^{11}$ & $\begin{array}{l}\text { Measures the effects of hearing } \\
\text { impairment on the emotional } \\
\text { and social adjustment of adults } \\
\text { Explores the perceived usefulness } \\
\text { of hearing aids }\end{array}$ & 7 & 11 \\
\hline
\end{tabular}

Abbreviations: HHIE, Hearing Handicap Inventory for the Elderly; HHIA, Hearing Handicap Inventory for Adults; IOI-HA, International Outcomes InventoryHearing Aids; QoL, quality of life. 
residual activity limitations; satisfaction; residual participation restrictions; impact on others; and quality of life. ${ }^{12}$

Generic QoL measures do not focus on any particular disorder or treatment, but rather on the self-perceived overall health status of the individual. Those most commonly administered, together with hearing-related tools, in order to understand the overall QoL level of the subjects, are:

- The MOS 36-Item Short Form Health Survey (SF-36). The SF-36 consists of 36 items that assesses eight health concepts: (1) limitations in physical activities because of health problems; (2) limitations in social activities because of physical or emotional problems; (3) limitations in usual role activities because of physical health problems; (4) bodily pain; (5) general mental health (psychological distress and well-being); (6) limitations in usual role activities because of emotional problems; (7) vitality (energy and fatigue); and (8) general health perceptions. It has been used by several authors to evaluate the level of mental and physical activity in subjects affected by hearing loss. ${ }^{9,12}$

- The Social Functioning Questionnaire. It has been proposed by several authors to investigate the social behavior and dimension of those affected by presbycusis. ${ }^{9,12}$ This is an eight-item, self-rating scale (score range 0-24) covering the most important domains of social life, such as work, home activities, finances, spare time activities, and social, family, and sexual relationships. It has been used in combination with the revised version of the Symptom Checklist-90, which is a valid and reliable psychiatric multidimensional self-report inventory, used to screen for psychopathological symptom patterns and levels of distress in community and medical responders (such as somatization, obsessive-compulsive behaviors, depression, anxiety, and hostility)..$^{9,12}$

Following the administration of the above-mentioned tools, a list of realistic patient goals can be identified and developed by otolaryngologists and audiologists. Those tools have been crafted in order to investigate and meet patient demands; expectations of prosthesization have increased due to the commercial promotion of certain hearing aid features, such as adaptive directional microphones and environmental noise reduction. The determination of comprehensive patientspecific goals will assist otolaryngologists and audiologists in the selection of specific features as they apply them to the needs of their patients.

Those instruments have been developed with the intent of building a foundation for evidence-based clinical practice guidelines in hearing rehabilitation; clinical practice guidelines can minimize variability in outcome, maximize treatment efficacy, reduce risks, decrease waste, improve patient satisfaction, and help to elevate the awareness of the profession of audiology among third-party payers, other health care providers, and, most importantly, current and future patients. As otolaryngologists and audiologists continue to compete in the health care marketplace, they can demonstrate that hearing rehabilitation reduces activity limitations, decreases participation restrictions, and improves health-related quality of life. Only by measuring outcomes can otolaryngologists and audiologists be assured that hearing rehabilitation makes a difference and that patients have benefited from their care. ${ }^{13}$

Nonetheless, a major drawback of these tools, as for other QoL scales, is related to the fact that the importance of different QoL dimensions can vary among individuals and within individuals over time, which means that structured measures may be inaccurate or insensitive. ${ }^{14}$

\section{Quality of life and presbycusis: present data}

Interestingly, among the population with hearing loss, only $39 \%$ of the subjects perceive that they have an excellent global QoL level or very good physical health, compared to $68 \%$ of those without hearing loss. Nearly one-third of the population with hearing loss report being in fair or poor health, compared to only $9 \%$ of the population without hearing loss; people with hearing loss are less satisfied with their "life as a whole" than people without hearing loss. ${ }^{15}$

When investigating the effects of hearing loss on QoL, presbycusis has been reported to be the cause of reduced communicative relationships, as well as reduced social and emotional interactions. ${ }^{16}$ In particular, it is reported to be a source of loneliness, isolation, and decline in social activities, as well as communication disorders and dissatisfaction with family life. ${ }^{16}$

As a result of maladaptive communication strategies, those with hearing loss are reported to perceive their social skills as poor, and thus, they also may experience reduced self-esteem if a combination of hearing impairment and a poor coping strategy contributes to failure in their roles. Moreover, some authors have stated that some patients are afraid to consider hearing loss a problem and subsequently are afraid to seek medical help for the hearing loss. This may potentially lead hearing impaired individuals to a further level of disability and handicap. ${ }^{9}$

It would be helpful if primary care physicians would test routinely for hearing impairment in adults and regularly refer those with hearing impairment to audiological tertiary care centers. ${ }^{9}$ 


\section{Quality of life after rehabilitation with hearing aids}

The benefits and satisfaction of using hearing aids among hearing-impaired elderly people have been explored in some studies. ${ }^{17,18}$

Joore and colleagues ${ }^{19}$ demonstrated that new hearing aid users experienced less anxiety and depression following hearing aid use. Mulrow et $\mathrm{al}^{20}$ also reported a reduction in depression among hearing aid users, as measured by a geriatric depression scale. ${ }^{21}$ In addition, Joore et $\mathrm{al}^{22}$ and Stark and Hickson $^{23}$ reported improvements in selected domain scores on the SF-36 as a result of hearing aid use..$^{22,23}$

In a large, multi-site study, McArdle et $\mathrm{al}^{24}$ administered both generic and hearing-related QoL measures to 380 participants randomized into experimental (immediate hearing aid treatment) and control (delayed hearing aid treatment) groups. Hearing aids were shown to improve both generic and hearing-related QoL domains, although the improvement in QoL was stronger as measured by the hearing-specific measures. ${ }^{24}$

Reductions in both emotional and social consequences of hearing loss after wearing hearing aids have been measured by the HHIE in some studies. ${ }^{23-27}$ Particularly in their metaanalysis, Chisolm et al ${ }^{18}$ showed that hearing aids improved adults' HHIE scores by reducing the psychological, social, and emotional effects of hearing loss. ${ }^{18,28}$ Cox et $\mathrm{al}^{29}$ also investigated different types of hearing aids and their impact on QoL, concluding that programmable hearing aids provide the most efficient effects. ${ }^{18,29}$

Only a few studies have focused on the effects of restoring binaural hearing and consequences for QoL. It has been demonstrated that binaural hearing aid wearers may benefit from the ability of the central auditory system to integrate binaural information and enjoy benefits such as binaural loudness summation, difference in masking level, localization, and elimination of head-shadow. ${ }^{17,30,31}$ It has been reported that, globally, about $80 \%$ of patients with severe, bilateral hearing loss wear hearing aids binaurally; therefore, patients with symmetric hearing loss should be more comfortable with binaural hearing aids. ${ }^{17,30,31}$

Finally, looking at cost-effectiveness analysis, Joore et al reported that using a hearing aid and returning hearingimpaired people to an ordinary lifestyle is cost effective. ${ }^{32}$ In addition, Chao and $\mathrm{Chen}^{30}$ stated that, for hearing-impaired elderly people, the use of hearing aids can be considered a cost-effective strategy for rehabilitation. ${ }^{17,30,31}$ Based on the average gain in hearing-related QoL, the outcome per year after the intervention could range from $€ 1333$ to $€ 3889 .{ }^{30,32}$
Different degrees of hearing loss, successful rates of hearing aid use, and rates of satisfaction with hearing aid use are main factors that affect this estimate..$^{30,32}$

\section{Conclusion}

Presbycusis is a complex disease, with a controversial physiopathology, which is influenced by genetic, environmental, and medical factors. It is an increasingly important public health problem that can lead to reduced quality of life, isolation, dependence, and frustration.

In the near future, it will be necessary to improve our knowledge of this condition and its physiopathology, in an attempt to remediate its progression. In addition, it will be of great importance to improve methods of identifying individuals with presbycusis and deteriorating QoL, thus improving services for providing hearing aids, assistive listening devices, and auditory rehabilitation. Identifying individuals with hearing loss, supplying appropriate hearing aids or other listening devices, and teaching coping strategies may have a positive impact on the quality of life of older people.

\section{Disclosure}

The authors report no conflicts of interest in this work.

\section{References}

1. Dalton DS, Cruickshanks KJ, Klein BE, Klein R, Wiley TL, Nondahl DM. The impact of hearing loss on quality of life in older adults. Gerontologist. 2003;43(5):661-668.

2. Gates GA, Mills JH. Presbycusis. Lancet. 2005;366(9491): 1111-1120.

3. Heine C, Browning CJ. Communication and psychosocial consequences of sensory loss in older adults: overview and rehabilitation directions. Disabil Rehabil. 2002;24(15):763-773.

4. Huang Q, Tang J. Age-related hearing loss or presbycusis. Eur Arch Otorhinolaryngol. 2010;267(8):1179-1191.

5. Tremblay K, Ross B. Effects of age and age-related hearing loss on the brain. J Commun Disord. 2007;40(4):305-312.

6. Ciorba A, Benatti A, Bianchini C, et al. High frequency hearing loss in the elderly: effect of age and noise exposure in an Italian group. J Laryngol Otol. 2011;125(8):776-780.

7. Bovo R, Ciorba A, Martini A. Environmental and genetic factors in age-related hearing impairment. Aging Clin Exp Res. 2011; 23(1):3-10.

8. Felce D, Perry J. Quality of life: its definition and measurement. Res Dev Disabil. 1995;16(1):51-74.

9. Monzani D, Galeazzi GM, Genovese E, Marrara A, Martini A. Psychological profile and social behaviour of working adults with mild or moderate hearing loss. Acta Otorhinolaryngol Ital. 2008;28(2): 61-66.

10. Weinstein BE, Spitzer JB, Ventry IM. Test-retest reliability of the Hearing Handicap Inventory for the Elderly. Ear Hear. 1986;7(5):295-299.

11. Newman CW, Weinstein BE, Jacobson GP, Hug GA. The Hearing Handicap Inventory for Adults: psychometric adequacy and audiometric correlates. Ear Hear. 1990;11(6):430-433.

12. Cox R, Hyde M, Gatehouse S, et al. Optimal outcome measures, research priorities, and international cooperation. Ear Hear. 2000;21(Suppl 4): $106 \mathrm{~S}-115 \mathrm{~S}$ 
13. Valente M, Abrams H, Benson D, et al. Guidelines for the audiologic management of adult hearing impairment. Audiol Today. 2006; 18(5):1-44.

14. Carr AJ, Thompson PW, Kirwan JR. Quality of life measures. Br J of Rheumatol. 1996;35(3):275-281.

15. The National Council on the Aging. The Consequences of Untreated Hearing Loss in Older Persons. Washington, DC: The National Council on the Aging 1999. Available from: http:/www.hearingoffice.com/ download/UntreatedHearingLossReport.pdf. Accessed 23 May, 2012.

16. Lotfi Y, Mehrkian S, Moossavi A, Faghih-Zadeh S. Quality of life improvement in hearing-impaired elderly people after wearing a hearing aid. Arch Iran Med. 2009;12(4):365-370.

17. Tsakiropoulou E, Konstantinidis I, Vital I, Konstantinidou S, Kotsani A. Hearing aids: quality of life and socio-economic aspects. Hippokratia. 2007;11(4):183-186

18. Chisolm TH, Johnson CE, Danhauer JL, et al. A systematic review of health-related quality of life and hearing aids: final report of the American Academy of Audiology Task Force On the Health-Related Quality of Life Benefits of Amplification in Adults. J Am Acad Audiol. 2007;18(2):151-183.

19. Joore MA, Potjewijd J, Timmerman AA, Anteunis LJ. Response shift in the measurement of quality of life in hearing impaired adults after hearing aid fitting. Qual Life Res. 2002;11(4):299-307.

20. Mulrow CD, Aguilar C, Endicott JE, et al. Quality-of-life changes and hearing impairment: a randomized trial. Ann Intern Med. 1990; 113(3):188-194

21. Yesavage JA, Brink TL, Rose TL, et al. Development and validation of a geriatric depression screening scale: a preliminary report. J Psychiatr Res. 1982-1983;17(1):37-49.
22. Joore MA, Brunenberg DE, Chenault MN, Anteunis LJ. Societal effects of hearing aid fitting among the moderately hearing impaired. Int $J$ Audiol. 2003;42(3):152-160.

23. Stark P, Hickson L. Outcomes of hearing aid fitting for older people with hearing impairment and their significant others. Int J Audiol. 2004 ; 43(7):390-398.

24. McArdle R, Chisolm TH, Abrams HB, Wilson RH, Doyle PJ. The WHO-DAS II: measuring outcomes of hearing aid intervention for adults. Trends Amplif. 2005;9(3):127-143.

25. Malinoff RL, Weinstein BE. Measurement of hearing aid benefit in the elderly. Ear Hear. 1989;10(6):354-356.

26. Abrams HB, Hnath-Chisolm T, Guerreiro SM, Ritterman SI. The effects of intervention strategy on self-perception of hearing handicap. Ear Hear. 1992;13(5):371-377.

27. Chmiel R, Jerger J. Hearing aid use, central auditory disorder, and hearing handicap in elderly persons. J Am Acad Audiol. 1996;7(3):190-202.

28. Chisolm TH, Abrams HB, McArdle R. Short- and long-term outcomes of adult audiological rehabilitation. Ear Hear. 2004;25(5):464-477.

29. Cox RM, Alexander GC, Gray GA. Who wants a hearing aid? Personality profiles of hearing aid seekers. Ear Hear. 2005;26(1):12-26.

30. Chao TK, Chen TH. Cost-effectiveness of hearing aids in the hearingimpaired elderly: a probabilistic approach. Otol Neurotol. 2008; 29(6):776-783.

31. Antonucci TC. Social supports and social relationships. In: Binstock RH, George LK, editors. Handbook of Aging and the Social Sciences. San Diego: Academic Press; 1990.

32. Joore MA, Van Der Stel H, Peters HJ, Boas GM, Anteunis LJ. The costeffectiveness of hearing-aid fitting in the Netherlands. Arch Otolaryngol Head Neck Surg. 2003;129(3):297-304
Clinical Interventions in Aging

\section{Publish your work in this journal}

Clinical Interventions in Aging is an international, peer-reviewed journal focusing on evidence-based reports on the value or lack thereof of treatments intended to prevent or delay the onset of maladaptive correlates of aging in human beings. This journal is indexed on PubMed Central, MedLine, the American Chemical Society's 'Chemical Abstracts Ser-

\section{Dovepress}

vice' (CAS), Scopus and the Elsevier Bibliographic databases. The manuscript management system is completely online and includes a very quick and fair peer-review system, which is all easy to use. Visit http://www.dovepress.com/testimonials.php to read real quotes from published authors. 